Article

\title{
An Exploration of Cultural Factors and Their Influence on Saudi Arabian University Deans' Leadership Perceptions and Practices
}

\author{
Yousef Abu Alsuood and Andrew Youde * \\ School of Education and Professional Development, University of Huddersfield, Huddersfield HD1 3DH, UK; \\ Yousef.AbuAl-Suood@hud.ac.uk \\ * Correspondence: a.youde@hud.ac.uk; Tel.: +44-(0)1484-478252
}

Received: 30 March 2018; Accepted: 18 April 2018; Published: 20 April 2018

\begin{abstract}
This article reports an investigation into societal and organizational cultural influences on academic leadership in Saudi Arabian higher education, a previously underexplored area. In Saudi Arabia, it is currently unclear how university deans are negotiating the balance between organizational cultural values and contemporary influences, and how the values they embrace may influence their leadership practices and effectiveness. The study has been conducted in eight main governmental universities under the Ministry of Education. Qualitative data has been collected, involving interviews with fifteen university deans, with data scrutinized by an interpretive thematic analysis. The deans' responses indicated dissatisfaction with the broad societal culture around them and the negative influence this had on leadership practices. Tensions were apparent between traditional values and change, and the influence of family and tribal backgrounds. Five organizational cultural themes were identified as influences on deans' leadership — a centralized environment, strict regulations, the authority of top management, selection and promotion issues, and reputational factors. The study's outcomes contribute to the understanding of leadership perceptions and practices within a particular cultural context.
\end{abstract}

Keywords: leadership; organizational culture; societal culture; Saudi Arabia; higher education

\section{Introduction}

Whilst there is a growing literature on the relationship between organizational and societal culture and educational leadership (for example, see [1-3]), little is known of any such influence within a context of Saudi Arabian higher education. This article seeks to address this gap. Institutions of higher education need to develop leaders that are well-grounded in functional skills [4]. Therefore, it is essential for these leaders to have the necessary leadership knowledge to ensure competency in practice as well as sensitivity to a diversity of beliefs and social forces. Further, educational leaders must be aware of the impact of their organizational and societal culture on their leadership as it forms the context of practice and influences how they both think and act [1] (p. 70).

Academic deans in Saudi Arabian higher education, as members of their university president's cabinet, are in a unique position to share leadership responsibility for the institution as a whole. They require a broad understanding of their university's concerns and strategic direction, while remaining involved in the practicalities of delivering effective teaching and research within their faculties [5] (p. 1). In higher education, effective leadership is imperative to a university's success, with presidents relying heavily on deans to provide internal leadership [6]. Their role mirrors notions of 'new managerialism', where corporate practices and values, such as performance appraisal, benchmarking and quality assurance, are being adopted by public sector organizations $[5,7]$. Universities implementing such 
practices often require compromise as traditional and new management regimes commonly operate in tandem [7] (p. 51). Deans must plan, organize, and control [8], whilst influencing decision making, shaping the curriculum, and playing a major role in developing a university's culture [9].

Idris [10] highlighted the growing suggestion that the context of leadership in the Kingdom of Saudi Arabia requires development in terms of cultural values that have been deeply inherited over time. Further, what might be considered an effective leadership style in one context may not be applicable in others [11] (p. 121). Hence, the emphasis of this study is to research and understand the impact of administrative culture, education, societal factors, and economic status on dean's leadership in Saudi Arabian governmental universities. Further, the study's contribution lies in bringing to the surface these tensions whilst shedding light on the ongoing dynamics in Saudi higher education as seen and practiced by people who are daily engaged in the process. The findings can help both university leaders and the Saudi Arabian Ministry of Education to better understand the complexity of leadership perspectives and practices in their organizational and national contexts.

The underpinning research reported in this article was guided by the following research questions:

- How did societal culture influence university organizational culture and leadership practices?

- How did organizational and societal cultural factors influence a dean's leadership experiences and practices?

\section{Research Context}

Higher education in Saudi Arabia is concomitant to Islamic principles, the basic ideology that colors the social and administrative lifestyles in the Kingdom [12]. University education is offered to both sexes, however, gender segregation is normal where men and women have their own separate campuses with most female branches supervised by males. According to the Ministry of Education, 26 public universities are now functioning in the Kingdom, with 16 of these being established in the last decade [13]. This serves to illustrate the significant modern expansion that has occurred in the country's educational system during the last decade. A number of initiatives underpinned this expansion.

In 2005, the government launched a significant educational initiative, the King Abdullah Scholarship Program (KASP), which aimed to support and sponsor Saudi students to pursue their higher education in other developed countries [14]. The scheme was supported and financed by the Government, with 174,333 Saudi students studying abroad in the 2015-16 academic year [15]. Further to this, in 2006, the Ministry adopted strategic guidelines from a national five-year plan that focused on developing the human resources at universities, with academic leadership development representing one of the key strands. Later, in 2009, the Ministry established a specific center called the Academic Leadership Center (ALC) to contribute to the development and spread of leadership culture that fosters innovation, success, and excellence [16].

Throughout the implementation of these initiatives, several challenges were facing higher education, particularly regarding trends in the international benchmarking of institutions. Notions of academic accreditation and world ranking are dominant in Saudi Arabian higher educational contexts, with many universities seeking Western benchmarking for their educational and research outcomes [17]. However, the struggle between globalization and the Saudi Arabian domestic cultural context is still coloring the transformation within the sector. As Pavan states:

At present, the Saudi vision of higher education is experiencing a struggle, rather than witnessing a reconciliation, between globalization and tradition. The issue is not simply a matter of importing or not importing Western-style higher education into the Kingdom. From a broader perspective, Saudi Arabia is confronted with a major challenge: to become a worldwide and authoritative economic and educational competitor, while retaining its freedom to decide what is the right and the best path to human development for its people. And here, forward educational plans can play a pivotal role. The outcomes of the Saudi 
experiment as this struggle to balance traditions and globalization could be defined, will impact not only on the country itself, but also on the Gulf region. [18] (p. 95)

Within these challenges, the question is can the current social reality of the Kingdom, with its effect on higher education, co-exist with the ongoing economic reform in the country? As a context for this article, this tension between societal national culture and the demand for rapid and transformative development is explored with regard to deans' leadership experiences and practices. Furthermore, despite increased numbers of faculty members having graduated from foreign universities, Alamri [19] states that only a few Saudi deans attempt to apply foreign approaches to leading their departments. In doing so, this approach has had negative affects due to the time and resource implications resulting from increased resistance from some subordinates.

\section{Literature Review}

Metcalfe \& Mimouni [20] (p. 180) state: 'there is a remarkable scarcity of solid studies on leadership theory and practices in Saudi Arabia', and this extends to higher education contexts. However, some studies have emerged to try and bridge this gap.

Alfayez [21] investigated the perceptions of the university's heads of departments at King Saud University regarding their leadership practices, including an analysis of gender differences. The research applied the Leadership Practices Inventory instrument [22] and surveyed 150 male and female department chairs, with the study finding no significant differences among the participants' perceptions of leadership practices based on gender, years of experience, and the academic rank. Alfayez pointed to the need for awareness of their leadership practices as a step towards becoming more professional academic leaders, advising that this would be beneficial to help the administration to deliver a more proficient and effective educational environment for the faculty and its students. However, not only did the research not consider contextual factors influencing the practices of leadership in Saudi Arabia, or even a classify distinctly certain leadership styles of respondents, the research was limited to one university. Furthermore, a quantitative approach was adopted to determine the most desirable practices of deans, with limited analysis of the circumstances behind such practices.

Gonaim and Peters [12] qualitatively investigated effective leadership characteristics and practices for female department chairs at one Saudi Arabian university. Despite its small-scale nature, the study's findings contribute to our understanding of the organizational and cultural factors that commonly affect chairs' leadership practice. Their research found challenges in dealing with people and with rules and regulations, but did not consider surrounding environmental factors when exploring academic leaders' practices.

Whilst there is a paucity of literature considering the cultural impact on Saudi Arabian higher education leadership practices, Alnaser [23] argued that there is also a need for appropriate training programs for this group and that they were ill-prepared for leading. Other Arab and Saudi Arabian leadership studies advised that the applicability of using Western leadership theories in isolation of local contextual factors should be viewed with relative caution [24,25]. Still, in spite of the extensive international research on leadership and culture, the limited research within Arab and particularly Saudi Arabian cultures, confirms the need for the current study with its particular focus on a sector (higher education in Saudi Arabia) and segment (university deans) that have not received sufficient attention.

\section{Conceptual Framework}

In order to explore the dean's lived experiences the data has been analyzed in relation to broad conceptions of organizational and societal culture together with Hofstede's notions of national cultural dimension. Spencer-Oatey defined culture as: 
A fuzzy set of attitudes, beliefs, behavioural norms, and basic assumptions and values that are shared by a group of people, and that influence each member's behaviours and his/her interpretations of the "meanings" of other people's behaviour. [26] (p. 4)

This alludes to the breadth and impact of the concept within particular contexts. Such groups of people can be conceptualized at various and interrelated levels including at an organizational level and a macro-national or societal level [27]. Dimmock and Walker [1] (p. 71) note that organizational cultures operates at a superficial level, and can be changed by leaders who influence, but are also influenced by, this culture. Whereas, societal cultures are influenced mostly at a level of basic values, are more enduring, and sit outside a leader's sphere of influence [1] (p. 71). National cultural values are learned early, held deeply and change slowly over the course of generations. Furthermore, they contribute to the influence of organizational culture $[27,28]$.

One of the most applicable frameworks for understanding differences based on national cultural dimensions is that proposed by Geert Hofstede [27-29]. He conducted a cultural value comparison study of over 66 different countries over 40 years ago, based on employees' attitudes and using the IBM subsidiaries. Working with this sample, Hofstede extracted four main dimensions of cultural differences in the workplace:

- Power distance, which focuses on the degree of equality, or inequality, between the citizens of a country.

- Individualism/collectivism, which focuses on the degree to which a society reinforces individual or collective achievement and interpersonal relationships.

- Masculinity/feminist, which focuses on the degree that the society reinforces, or not, the traditional masculine work role model of male achievement, control, and power.

- Uncertainty avoidance concentrates on the degree of tolerance for uncertainty and ambiguity within the society, and demonstrates the extent to which the citizens of a nation prefer structured over unstructured situations.

Later, Hofstede [27] developed a fifth dimension, long-term orientation, which illustrates the degree to which the society embraces long-term devotion to traditional, forward-thinking values. A number of studies have applied Hofstede's dimensions to investigate the Arab and Saudi Arabian societal cultures. Some of these are considered while discussing findings of the current study in relation to the national culture of Saudi Arabia (see Discussion section).

\section{Methodology}

The research aimed to investigate the interaction of leadership and culture within a particular context, therefore, an interpretivist philosophical approach [30] was adopted through the collection of qualitative data. This was because insight was sought into two subjective phenomena (leadership and culture), as perceived by the deans. This approach offered the ability for the researchers to identify issues from the perspectives of those leaders, and to comprehend their meanings and interpretations of their behavior, events or actions, in order to acquire a comprehensive understanding of the dean's overall experiences [31]. In addition, and corresponding with other social aspects of human behavior, leadership and culture are relative rather than absolute; they are dynamic and ever changing. Therefore, it is impossible to perceive a person through a common or static lens. Through creating and developing a level of trust and being situated close to the person's own context, the qualitative researcher is able to gather rich and in-depth data. One of the researchers is from Saudi Arabia and has lived there and worked in higher education for a number of years. This brought deep insight into the phenomena of leadership perceptions and practices, and the broader cultural context of the research.

Fifteen semi-structured interviews were carried out with deans from eight governmental universities under the Ministry of Education's control. All of the deans were established in their careers and all are from an academic background (see Table 1 for background information about the 
deans). All the deans interviewed are male, since female education is legally separated in the Saudi Arabian context.

Table 1. Background information about the deans.

\begin{tabular}{|c|c|c|c|c|c|}
\hline Pseudonym & $\begin{array}{c}\text { Years of } \\
\text { Experience } \\
\text { as a Dean }\end{array}$ & Age Group & $\begin{array}{l}\text { Academic } \\
\text { Rank }\end{array}$ & $\begin{array}{l}\text { Research and } \\
\text { Qualification } \\
\text { Background }\end{array}$ & Location \\
\hline D-1 & $5-10$ & $46-55$ & Associate & Humanities & Dammam \\
\hline D-2 & $3-5$ & $46-55$ & Assistant & $\begin{array}{c}\text { Medical and } \\
\text { Health Sciences }\end{array}$ & Medina \\
\hline D-3 & $10-20$ & $46-55$ & Assistant & Humanities & Riyadh \\
\hline D-4 & $5-10$ & $46-55$ & Associate & Science & Jeddah \\
\hline D-5 & $10-20$ & Over 55 & Associate & Humanities & Dhahran \\
\hline D-6 & 5-10 & $36-45$ & Assistant & $\begin{array}{l}\text { Computer } \\
\text { sciences }\end{array}$ & Shagra \\
\hline D-7 & $10-20$ & $46-55$ & Assistant & $\begin{array}{l}\text { Computer } \\
\text { Sciences }\end{array}$ & Makkah \\
\hline D-8 & 5-10 & $36-45$ & Assistant & $\begin{array}{c}\text { Medical and } \\
\text { Health Sciences }\end{array}$ & Makkah \\
\hline D-9 & $5-10$ & $36-45$ & Associate & $\begin{array}{l}\text { Medical and } \\
\text { Health Sciences }\end{array}$ & Makkah \\
\hline D-10 & $3-5$ & $36-45$ & Assistant & $\begin{array}{c}\text { Medical and } \\
\text { Health Sciences }\end{array}$ & Baha \\
\hline D-11 & $3-5$ & $36-45$ & Assistant & Science & Makkah \\
\hline D-12 & 5-10 & Over 55 & Professor & Engineering & Jeddah \\
\hline D-13 & $10-20$ & Over 55 & Assistant & Science & Jeddah \\
\hline D-14 & $5-10$ & Over 55 & Professor & Science & Jeddah \\
\hline D-15 & $3-5$ & $36-45$ & Assistant & Engineering & Abha \\
\hline
\end{tabular}

The semi-structured interviews questions were developed from a review of other studies in the field of leadership in higher education, and particularly those focused on the behavior of deans as academic leaders and their experiences. To explore and consider unique features of the dean's experiences and practices, an active interviewing approach was adopted [32] that presented a range of questions, allowing in-depth discussions of issues.

Template analysis was chosen to analyze the interview data given its value when comparing respondents' views within a specific context and its suitability for anti-positivistic, idiographic research [33]. King [33] (p. 256) argues that template analysis is not a single method or research itself, or a methodological position, but a series of techniques for the inductive analysis of textual, or in this case, interview data. A review of literature identified a range of issues for the interview to explore and these formed the basis of the a-priori codes identified for the first template. However, some flexibility was required in template development and subsequent analysis, particularly, in relation to culture. Template analysis afforded the exploration of broad themes, but allowed amendments when new factors were emerging from the data.

\section{Findings}

This section firstly considers the data in relation to the involvement of societal culture, before moving onto discuss themes arising around organizational culture. 


\subsection{Influence of Societal Culture}

This section provides a discussion of deans' perceptions in terms of a broad evaluation of the culture in which they work.

Twelve of the interviewed deans stated the culture surrounding them was demotivating when seeking to deliver effective leadership, with one stating:

The culture is not motivating for deans, with the proof being that many refuse to become deans, or to renew their contract of employment, and I am one of them. (D-8)

Partial criticism of societal culture's dominance was freely noted by the deans. Four respondents referred to the need for transformational thoughts among those holding higher positions in the educational system in order to change the influence of such societal culture, and for academic leaders to refine their behavior as well as their skills. The following quote is an example of the perceived impact of societal cultural on the deans' performance:

We are a society which is controlled by our culture, the society we live in and the environment in which we grew up ... Actually, I am not satisfied, because there is still cultural and social dominance controlling the basic leading concepts, so the main driver of these matters in the administrative educational leadership world is the culture of the society in which the dean lives. (D-13)

This dean continued by referring to a transformation occurring while also pointing to the need for development to cope with, and change, the prevailing culture:

There is change without doubt that exists, but I am still not satisfied. From my point of view and experience, the more deans or faculty members participate on courses to refine their skills and values to change the culture around them, the more effective they will be. If not, we will lose. (D-13)

When explaining the reasons behind the level of dissatisfaction in terms of their culture, the deans referred to the term 'wasta' or social mediation. Wasta is an Arabic word referring to "the interventions of a patron in favor of a client in attempt to obtain privilege or resources from a third party" [34] (p. 412), and is a societal culture aspect that can be perceived negatively. One dean stated:

The most dominant factor in our surrounding environment is "personal connection" or "mediation for others"; it is one of the most important factors that prevents development in Arab countries. All other factors are minor compared with this factor. Personal connection and social connection all affect the environment. (D-1)

The deans generally viewed this as an internal factor in regard to their relationship with higher management within their university, with this linking to organizational cultural factors outlined in the next section.

A further area of societal reflection inside universities is the perception of Islamic values. Although reference to Islamic values among the participant deans was at a low level, one interviewee referred to this as an ideal model of behavior that deans should follow. Another touched on a rather sensitive issue related to the application of Islamic social values, where social conflict has been occurring in Saudi Arabia between two schools of thought on perceiving Islam. One tends to be "Conservative", while the other is more "Liberal" and open to new thoughts. Both positions have support inside the community and, therefore, inside universities. The following dean referred to them as "powers", which implies a sense of soft power that is constructed based on the intellectual networking within the university:

Many social parties interfere with your work, such as religious institutions. Each one attempts to dominate the culture in their own particular way. These powers could be social, 
family or currently controlling parties.... Different intellectual schools have conflict between them, and you as a leader may fall as a ball, thrown between the opposing parties. However, in fact, they affect us and keep us in the zone of caution. This affects the work of deans. (D-5)

In spite of its minor reference in the narratives, this notion of competing schools of thought contributes to the ensuing conflict between traditional values and their modern counterparts, not only in Saudi society, but also within universities. It extends deeply into the establishment of the country, where the flowering of the conservative ideology of Wahhabism now has a counterpart view that seeks social modernization. Moreover, D-5 referred to the issue of family as a power that influences deans, which reflects a degree of tribal values among them. This family component contributed to the effect of outside influence on this dean since his further discussion regarding the competing schools of thought's influence was widely evident through his narrative. However, the deans tended not to professionally interact directly with people from the broader society as part of their day-to-day practices, which potentially limits the impact of this notion.

To summarize, the deans' responses clarified their dissatisfaction with the predominant societal culture around them and the negative influence on leadership practices. Tensions were apparent between traditional values and change and the influence of family and tribal backgrounds. Although a small number of deans cited these societal issues, the majority reported on the organizational cultural factors, which are considered in the next section. Nevertheless, these societal values are linked to the organizational issues presented, since the study argues that organizational culture is influenced by this national societal culture.

\subsection{Influence of Organizational Culture}

Following data analysis and, although there were some overlaps, five prominent themes emerged around leadership practices and perceptions, and organizational culture. A final issue, human resources, is included as an example of how broader organizational cultures can impact on dean's day-to-day practices. The themes are listed below and considered in turn:

- regulations;

- centralization;

- influence of top management;

- selection and promotion;

- reputation;

- human resource issues.

\subsubsection{Regulations}

Within this research we considered regulations as a component of the surrounding cultural factors of the universities under investigation. Politically, Saudi Arabia is considered as a conservative country within the region, featuring a strict hierarchy supported by regulations. General responses from the deans to this issue comprised of two dimensions: the first lay in their perception of regulations as obstacles; while the second was grounded on the issue of flexibility in adherence to regulations.

Seven of the respondents reported that regulations were an obstacle, and that deans were strongly linked to them, for example:

I think it [regulation] can be somewhat limiting. Sometimes you plan for some changes and the regulations then contradict this. So, I believe the current regulations, to some extent, affect the development process [in Saudi Arabia]. (D-5)

While it was found through the narratives that regulations are an obstacle, the deans' attitudes in terms of how to use or navigate the regulations also appeared relevant. Three other deans outlined that regulations did not prevent them from achieving their goals per se, and that it was possible to engage with the "spirit" of these regulations. In spite of the different scope used to report the category 
of regulation, D-10 supported the argument that although regulations are strict and inflexible, leaders do still have a margin to achieve goals by focusing on the intention with which they were created. For the majority of the deans, in the context of organizational culture of regulation, they reported it as being strict and unchangeable, despite some seeing opportunities to navigate through these to achieve certain goals.

\subsubsection{Centralization}

Developing the above notion regarding regulations is consideration of the impact of centralization within Saudi Arabian higher education. Again, this external control was broadly perceived by the deans as having a negative impact on their work. All respondents noted the strength of centralization, for example D-1 stated:

An academic leader travels a long path to achieve something or take a decision.... We really lack flexibility.... There is strong centralization. The first characteristic of our academic life is that it is centralized. (D-1)

Views pointed to a lack of flexibility coupled with extensive bureaucracy as key implications of the centralization present in their universities. D-1, however, pointed to an interesting notion that entails the extent of the organizational culture's influence on deans' perceptions, and accordingly their practice. He criticized the academic environment as being centralized, and then urged the deans to look beyond centralization:

When dealing with academics that hold high degrees, the dean should be flexible, listening rather than issuing orders. He needs to create working teams to support him rather than relying on centralization. (D-1)

Such external control is commonly facilitated by the influence and actions of Saudi Arabian university senior managers.

\subsubsection{Influence of Top Management}

Within Saudi Arabia, the Presidents of all governmental universities enter into their position via a royal appointment from the King. They are given a title and an administrative position that is similar to a minister. Inside universities, Presidents have full authority. Meanwhile, deans are appointed as a result of a decision from the Minister of Education, based on the respective institutional President's recommendation.

Six of the interviewed deans stated that their relationship with the higher management was not healthy or supportive, with the following quotes illustrating this unfavorable position:

Frustration with the top management is an issue, since deans need to cooperate with the higher management to solve problems and participate to find solutions related to the educational institution. (D-10)

I think that the high management always reject the decisions made by the faculty, which leads to limited decisions being implemented inside the faculty. (D-11)

These excerpts support the high authority given to university Presidents and how this influences the deans in their daily work, and in D-11's case, he needed to wait for the approval of decisions from the President's team, which were commonly declined. In a community that is centralized and features a strict hierarchy, these aspects would seem to be a natural outcome as a person with authority is respected, with some preferring to avoid challenge. However, reliance on the President's bureaucratic authority appears to negatively impact on the deans' work.

The influence of hierarchy and the impact on dean's practices was exemplified in this quote: 
Our selection process makes the management hierarchical, in the sense that you don't manage to support those who are under you, but you try to manage in a way that satisfies the person above you. Consequently, the focus in the administrative process is not on the institutional success, but rather the gratification of the top management. (D-15)

This reflects an important issue relevant to the nature of such a collective society that conveys great value and respect to hierarchy and authority. However, D-15's final observation on the emphasis on satisfying superiors implies a connection to another organizational category related to "reputation", which will be discussed later in this section.

\subsubsection{Selection and Promotion}

As an organizational cultural category influencing the deans' behavior, the selection and promotion of deans received the greatest input and interest from the respondents. Three issues were raised by the deans: the absence of criteria, the effect of academic rank, and the effect of personal relations with top management.

Seven of the interviewed deans reported the absence of sound and efficient criteria for selecting deans. D-9 developed this argument further when stating that appointments are made based on seniority and academic experience, rather than leadership experience.

The deans described that promotions from associate or full professor to dean was highly linked to their research contributions, as opposed to their leadership capabilities. Consequently, they voiced tensions between their management duties and other research and teaching commitments. This was exacerbated when academic rank was taken as a main criterion for selection. Eight deans stated that academic rank was not necessary as a criterion for selection. In addition, D-5 complained about the effect of academic rank on his work, reflecting that deans suffer while their colleagues advance in their academic and research careers. Relying on academic rank for the deans' selection was thus perceived by the majority of the respondents as having a negative impact on their leadership practice.

The third factor impacting on the deans' selection is the effect of relations with top management. Strong criticisms were voiced by ten deans regarding the influence of personal connections to top management during the recruitment and selection process. Similar to wasta (see Influence of Societal Culture section), this issue reflects societal and national cultural values, and particularly tribalistic ones, and high power distance attributes as per Hofstede [28], since the deans have to please the top management in order to be appointed.

The comments regarding the top management's involvement in the deans' selection and promotion reflected similar notions to those noted earlier on the absence of clear criteria to select deans and the influence of academic rank. All three of these factors are shaping the organizational culture with the majority of the respondents noting these as having a negative impact on practices.

\subsubsection{Reputation}

Reputation as a cultural category exemplifies the nature of a collective society, where centralization is dominant and high power is given to the superior in the administrative hierarchy, while other levels of management attempt to please the top management by exaggerating their performance and concentrating on its perceived appearance. This view from three deans, although relatively limited among the overall sample, appears to be consistent with the perceptions of the categories discussed above, particularly centralization and the influence of higher management. D-8 stated:

The university President tends to concentrate on the outside shape of the dean's performance. Provided that you market the outside shape of achievement well, you will stay as a dean. (D-8)

D-2 noted the importance external reputation that is demanded by top management and Saudi Arabian society in general. He cited "what is written in newspapers" and "the number of conferences organized" as examples. Therefore, he argued, performance may be embellished to inform society, and by default the University top management, of their achievements. 


\subsubsection{Human Resource Issues}

Developing the above themes, this section considers human resource issues as an example of how broader organizational cultures can impact on dean's day-to-day practices. Deans raised a number of human resource issues, particularly concerning their workloads and their control over subordinates, which were influenced by the Ministry of Education's central control.

Nine of the respondent deans described dissatisfaction with the distribution of workloads and administrative pressures they faced, with this negatively influencing their performance. This impact was compounded as these deans described a weak level of delegation regarding distribution of their work tasks due to the influence of centralization. They felt they had little control over staffing. As faculty leaders inside governmental universities, they do not have the right to hire personnel or even terminate their employment. This is because they are civil officials that are hired by the Government. The only available option for unproductive staff is to circulate them between administrative departments with six deans describing that the administrative subordinates available to them were not effective. This view about the quality of subordinates appeared to explain why deans engage themselves in minor administrative details and did not delegate.

\section{Discussion}

Due to the tribal nature of the Saudi Arabian community [35] and the collectivist nature of its social and cultural society [28], a strict hierarchy was noticed in the context of Saudi higher education. Deans' views regarding this, such as those raised about centralization, regulation, and the influence of top management, express the nature of a tribal society [35]. The influence of hierarchy, power of top management and strict regulations were frequently mentioned by the deans when explaining the cultural pressure imposed on their leadership practices. Hofstede's [28] dimension of Uncertainty Avoidance reveals the extent to which a society will accept ambiguity and uncertainty. As a rule-oriented society, he asserts that Saudi Arabia generally tends towards uncertainty avoidance and working under centralized control with extensive rules and regulations, which is supported by the findings of this study. The deans strongly emphasized the dominance of rules and centralization in their organizational lives. In addition, and in spite of their emphasis on the need to meet the spirit of these regulations, they were critical of the lack of flexibility and clarity.

The findings of this study reveal some similarities with previous published works regarding the influence of culture on leadership practices. However, the data that emerged on the effect of the cultural factors of leadership revealed interesting implications and tensions that reflect the nature of the ongoing social and cultural transitions in Saudi Arabia, which are being also experienced within higher education contexts. Traditional organizational cultural factors were evident, such as centralization, and despite criticisms regarding their negative impact on the leadership situation in their context, the deans recognized that this reflects the nature of Saudi society, including leadership in organizations. This is consistent with Gonaim and Peters' research [12], who found that Saudi culture helped to shape the characteristics and behaviors of effective department chairs in higher education, which included a conservative, social hierarchy underscored by a strong belief in the importance of respecting tradition. Further, Basahel's [36] research on three Saudi Arabian business organizations found a dominance of hierarchy cultures.

Factors within traditional dimensions of organizational culture were generally perceived negatively by deans. This reveals some consistency with previous cultural studies on Saudi Arabia and Arab culture in general. Trompenaars [37] found that the social status of Arabian communities, including Saudi ones, are conferred on the basis of personal background as opposed to individual achievement. This factor could be reflected in Hofstede's [28] uncertainty avoidance dimension, in which the Saudi Arabian score is particularly high $[29,38]$. This article's findings revealed that personal relationships, whether with top management or more generally in the external society, influenced the deans' performance and practices at work. Of particular significance with regard to this phenomenon was the selection and promotion of deans and practices that they engaged in to keep top management 
happy. Indeed, they linked these factors to the nature of culture, which echoes Hofstede's dimensions of uncertainty avoidance, power/distance and collectivism, where reliance of personal connections and family relations with people who hold authority plays a more significant role than professionalism and individual personal performance. This finding echoes previous studies' criticisms of the dominance of personal connections, particularly with presidents, as a cause of unsatisfactory job performance and organizational deficiency [39,40]. Moreover, there is resonance with Abdalla and Al-Homoud's [41] (p. 522) investigation of Arab managers, which highlighted "people from Arabic nations' concern with their interpersonal relationships, which translates into being one of Arab people's leadership characteristics". In addition, the level of trust and appreciation between high levels of authority and the deans appeared to be weak. Therefore, the practice of individualism was common and, in the context of this study, the deans represented role models who led by example.

The broad organizational cultural context impacted on deans' leadership behavior and practices on a more practical level. This was noticed in their responses regarding the lack of effective job descriptions, strong reliance on written rules, extensive meetings, alongside a heavy workload and frequent interruptions. This appears to be consistent with cultural studies of Saudi Arabia; for example, Aseri [42] found that Saudi Arabian managers showed a relatively strong reliance on both formal and unwritten rules, as did the coworkers and subordinates. Furthermore, these findings concur with Gonaim and Peters [12], who found that the female faculty chairs faced several challenges including ill-defined rules and regulations, and workload pressures. Such challenges also confronted deans, influencing their work and leadership perceptions and practices, with this going some way to explain their criticism of these cultural factors and the negative impact on their attitudes.

\section{Conclusions}

This study was conducted to explore Saudi Arabian societal and organizational cultural influences on university deans' leadership. It considered their perceptions of the culture in which they work and the impact it had on their practices. An important contributing dimension of this study lies in the intertwining of cultural, political and social influences on Saudi Arabian leadership, with this germane when leading in universities. They are administratively and financially controlled by the Government, therefore this dominates a leader's decision making. This, coupled with the importance of personal connections in Saudi Arabian society, influenced deans' perceptions and practices. The study suggests dissatisfaction with the societal culture around them and the negative influence this had on leadership practices. Tensions were apparent between traditional values and change, and the influence of family and tribal backgrounds. Five organizational cultural themes were identified as influences on deans-a centralized environment, strict regulations, the authority of top management, selection and promotion issues, and reputational factors. The study represents a contribution to the understanding of deans' leadership perceptions and practices in the context of Saudi Arabian higher education.

Acknowledgments: The authors wish to thank the deans who were interviewed as part of this research for generously giving up their time.

Author Contributions: Y.A.A. conceived, designed and collected the data for this research. The initial data analysis was undertaken by Y.A.A. with A.Y. supporting later iterations of this process. Both Y.A.A. and A.Y. wrote the article.

Conflicts of Interest: The authors declare no conflicts of interest.

\section{References}

1. Dimmock, C.; Walker, A. School leadership in context-Societal and organizational cultures. In The Principles and Practice of Educational Management; Bush, T., Bell, L., Eds.; Paul Chapman: London, UK, 2002; pp. 70-85.

2. Miller, P. Exploring School Leadership in England and the Caribbean: New Insights from a Comparative Approach; Bloomsbury: London, UK, 2016.

3. Miller, P. Cultures of Educational Leadership, Intercultural Studies in Education; Palgrave Macmillan: London, UK, 2017. 
4. Basham, L.M. Transformational and Transactional Leaders in Higher Education. Int. Rev. Bus. Res. Pap. 2010, 6, 141-152.

5. Lynn, V.; Goedegebuure, L.; Santiago, R.; Carvalho, T. Introduction. In The Changing Dynamics of Higher Education Middle Management; Meek, V.L., Goedegebuure, L., Carvalho, T., Santiago, R., Eds.; Springer: Dordrecht, The Netherlands, 2010; pp. 1-14.

6. Birnbaum, R. How Academic Leadership Works; Jossey-Bass: San Francisco, CA, USA, 1992.

7. Deem, R. 'New managerialism' and higher education: The management of performances and cultures in universities in the United Kingdom. Int. Stud. Sociol. Educ. 1998, 8, 47-70. [CrossRef]

8. Gmelch, W.H. The department chair's balancing acts. New Dir. High. Educ. 2004, 126, 69-84. [CrossRef]

9. Baskan, G.; Ercetin, S. Personal and Organizational Visions of the Deans in Turkish Universities for the New Millennium; Hacettepe University: Ankara, Turkey, 2000.

10. Idris, A.M. Cultural barriers to improve organizational performance in Saudi Arabia. SAM Adv. Manag. J. 2007, 72, 36-53.

11. Miller, P. The Nature of School Leadership: Global Practice Perspectives; Palgrave Macmillan: London, UK, 2018.

12. Gonaim, F.A.; Peters, F. Effective Leadership Characteristics and Behaviors for Female Department Chairs in Higher Education in Saudi Arabia. Eur. J. Educ. Stud. 2017, 3. Available online: www.oapub.org/edu/index. php/ejes/article/view/368 (accessed on 12 August 2017).

13. Ministry of Education. Available online: https://www.moe.gov.sa/EN/HIGHEREDUCATION/ GOVERNMENTHIGHEREDUCATION/STATEUNIVERSITIES/Pages/default.aspx (accessed on 12 June 2017).

14. Abouammoh, A.M.; Smith, L.R.; Duwais, A.M. A Review of Saudi Scholarship Programs to North American Higher Education Institutions. Int. J. Hum. Soc. Sci. 2014, 4, 41-49.

15. Ministry of Education. Available online: https://departments.moe.gov.sa/PLANNINGINFORMATION/ RELATEDDEPARTMENTS/EDUCATIONSTATISTICSCENTER/EDUCATIONDETAILEDREPORTS/ Pages/default.aspx (accessed on 17 January 2018).

16. Academic Leadership Center (ALC). Available online: http://www.alc.edu.sa/who-we-are.html (accessed on 12 September 2017).

17. Smith, L.; Abouammoh, A. Higher Education in Saudi Arabia: Achievements, Challenges and Opportunities; Springer: New York, NY, USA, 2013.

18. Pavan, A. Higher Education in Saudi Arabia: Rooted in Heritage and Values: Aspiring to Progress. Int. Res. High. Educ. 2016, 1, 91-100. [CrossRef]

19. Alamri, M. Higher Education in Saudi Arabia. J. High. Educ. Theory Pract. 2011, 11, 88-91.

20. Metcalfe, B.; Mimouni, F. Leadership Development in the Middle East; Edward Elgar: Cheltenham, UK, 2011.

21. Alfayez, A.F. Head of Departments' Leadership Practices at King Saud University in Saudi Arabia. Ph.D. Thesis, Saint Louis University, St. Louis, MO, USA, 2014.

22. Kouzes, J.M.; Posner, B.Z. The Leadership Challenge: How to Keep Getting Extraordinary Things Done in Organizations; Jossey-Bass: San Francisco, CA, USA, 1995.

23. Alnaser, Y. Training Needs and Training Programs for Academic Leadership at Northern Border University. Int. J. Hum. Cult. Stud 2016, 3, 140-146.

24. Shahin, A.I.; Wright, P.L. Leadership in the context of culture: An Egyptian perspective. Leadersh. Org. Dev. J. 2004, 25, 499-511. [CrossRef]

25. Alzoman, M. Effective Leadership of a Culturally Diverse Workforce in Saudi Arabia Basic Industries Corporation (SABIC). Ph.D. Thesis, University of Portsmouth, Portsmouth, UK, 2012.

26. Spencer-Oatey, H. Culturally Speaking: Managing Rapport through Talk across Cultures; Continuum: London, UK, 2000.

27. Hofstede, G. Cultures and Organizations: Software of the Mind; McGraw-Hill: Maidenhead, UK, 1991.

28. Hofstede, G. Culture's Consequences: International Differences in Work Related Values; Sage Publications: Beverly Hills, CA, USA, 1980.

29. Hofstede, G.; Hofstede, G.J.; Minkov, M. Cultures and Organizations: Software of the Mind: Intracultural Cooperation and Its Importance for Survival, 3rd ed.; McGraw Hill: London, UK, 2010.

30. Wellington, J. Educational Research: Contemporary Issues and Practical Approaches; Continuum: London, UK, 2000.

31. Hennink, M.; Hutter, I.; Bailey, A. Qualitative Research Methods; Sage Publications: Thousand Oaks, CA, USA, 2011. 
32. King, N. Using Interviews in Qualitative Research. In Essential Guide to Qualitative Methods in Organizational Research; Cassell, C., Symon, G., Eds.; Sage Publications: London, UK, 2004; pp. 11-22.

33. King, N. Using templates in the thematic analysis of text. In Essential Guide to Qualitative Methods in Organizational Research; Cassell, C., Symon, G., Eds.; Sage Publications: London, UK, 2004; pp. $256-271$.

34. Mohammad, A.A.; Mohammad, M.S. The effect of wasta on perceived competences and morality in Egypt. Cross Cult. Manag. 2011, 18, 412-425. [CrossRef]

35. Ali, S.; Raiden, A.; Krik, S. Wasta in Jordanian Culture: A Study in the Banking Sector. Int. J. Innov. Bus. 2013, 2, 529-550.

36. Basahel, S. The Effect of Organizational Culture and Leadership on CRM Implementation in Saudi Arabian Organizations. Ph.D. Thesis, Brunel University, London, UK, 2016.

37. Trompenaars, F. Riding the Waves of Culture: Understanding Cultural Diversity in Business; London Economist Books: London, UK, 1993.

38. Bjerke, B.; Al-Meer, A. Culture's consequences: Management in Saudi Arabia. Leadersh. Org. Dev. J. 1993, 14, 30-35. [CrossRef]

39. Kilani, A.; Sakijha, B. Wasta: The Declared Secret; Arab Arch: Amman, Jordan, 2002.

40. Loewe, M.; Blume, J.; Speer, J. How Favoritism Affects Business Climate: Empirical Evidence from Jordan. Middle East J. 2008, 62, 259-276. [CrossRef]

41. Abdalla, I.A.; Al-Homoud, M.A. Exploring the Implicit Leadership Theory in the Arabian Gulf States. Appl. Psychol. 2001, 50, 506-531. [CrossRef]

42. Aseri, M. Leadership: A Study of Global and Cultural Context in Saudi Arabian Organizations. Ph.D. Thesis, The University of Manchester, Manchester, UK, 2015.

(C) 2018 by the authors. Licensee MDPI, Basel, Switzerland. This article is an open access article distributed under the terms and conditions of the Creative Commons Attribution (CC BY) license (http:/ / creativecommons.org/licenses/by/4.0/). 